\title{
The Role of $\beta$-Arrestin I in Esophageal Squamous Cell Carcinoma
}

This article was published in the following Dove Press journal: OncoTargets and Therapy

\author{
Zhijie Tan' \\ Bin $\mathrm{Li} \mathbb{B}^{2}$ \\ Xia Dong ${ }^{3}$ \\ Wenxing $\mathrm{Liu}^{4}$ \\ Shanshan Liu' \\ 'Department of Gastroenterology, \\ People's Hospital of Central District of \\ Jinan, Shandong 250022, People's \\ Republic of China; ${ }^{2}$ Department of \\ Gastroenterology, Shandong Provincial \\ Hospital Affiliated to Shandong First \\ Medical University, Shandong 25002I, \\ People's Republic of China; ${ }^{3}$ Department \\ of Anesthesiology, People's Hospital of \\ Central District of Jinan, Shandong \\ 250022, People's Republic of China; \\ ${ }^{4}$ Department of General Surgery, \\ People's Hospital of Central District of \\ Jinan, Shandong 250022, People's \\ Republic of China
}

Correspondence: Bin Li

Department of Gastroenterology,

Shandong Provincial Hospital Affiliated to

Shandong First Medical University, No.

324, Jingwuweiqi Road, Jinan, Shandong,

People's Republic of China

Email BinLil234@yeah.net
Introduction: Esophageal squamous cell carcinoma (ESCC) is the predominant type of esophageal carcinoma with a low survival rate and a poor prognosis. Therefore, it is of great significance to explore the effective tumor markers in early diagnosis, treatment monitoring and prognosis evaluation of ESCC. The current study was designed to explore the important role of $\beta$-arrestin1 in ESCC and the underlying mechanism.

Methods: The defined effects of $\beta$-arrestin1 on cell proliferation, migration, invasion, EMT and tumor growth were investigated both in ESCC cells and in vivo model of ESCC. $\beta$-arrestin1 expression was detected using Western blot and immunohistochemistry assay. The cell proliferation ability was determined using CCK-8 assay. Wound healing assay and trans-well invasion assay were performed to determine cell migration and invasion. The key proteins related to cell migration, invasion and EMT were detected by Western blot. Tumor growth in vivo was also monitored by tumor volume and weight. In addition, the effects of $\beta$-arrestin 1 on AKT/GSK3 $\beta$ / $\beta$-catenin pathway were evaluated.

Results: $\beta$-arrestin1 was aberrantly upregulated in human ESCC tissues, ESCC cell lines and animal model of ESCC. $\beta$-arrestin1 downregulation inhibited cell proliferation, migration, invasion and EMT of ESCC in vitro and vivo. $\beta$-arrestin downregulation also suppressed tumor growth in vivo model of ESCC. In addition, the inhibitory effects of $\beta$-arrestin 1 downregulation were exerted via AKT/GSK3 $\beta / \beta$-catenin signaling pathway.

Discussion: The results in the present study together confirmed the truth that $\beta$-arrestin1 interference may suppress ESCC cell proliferation, migration, invasion, EMT and tumor growth via $\mathrm{AKT} / \mathrm{GSK} 3 \beta / \beta$-catenin signaling pathway.

Keywords: $\beta$-arrestin1, proliferation, invasion, migration, EMT, tumor growth

\section{Introduction}

Esophageal squamous cell carcinoma (ESCC), the predominant type of esophageal carcinoma, carries a poor prognosis and a low survival rate. ${ }^{1-4}$ Effective tumor markers will play an important role in early diagnosis, treatment monitoring and prognosis evaluation of ESCC.

Although a few of advances have been achieved in the early diagnosis and treatment of ESCC, the tumor invasion and metastasis are the main causes resulting in death. ${ }^{5}$ The invasion and metastasis abilities of tumor cells are obtained mainly through the epithelialmesenchymal transformation (EMT) process. ${ }^{6}$ EMT involves genes changes in tumor cells and epigenetic, which are closely related to tumor invasion and metastasis. ${ }^{7}$ Therefore, invasion, metastasis and EMT are the key periods in ESCC progress.

$\mathrm{PI} 3 \mathrm{~K} / \mathrm{Akt}$ and $\mathrm{Wnt} / \beta$-catenin signaling pathways are currently widely studied, which play an important role in cell survival, regeneration and apoptosis inhibition. ${ }^{8,9}$ 
Glycogen synthase kinase $3 \beta$ (GSK-3 $\beta$ ), an AKT signaling target, functions in diverse cellular processes including proliferation, differentiation, motility and survival. ${ }^{10}$ A recent research showed that knockdown of AKT1/2 suppressed cell proliferation and induced cell apoptosis in KYSE70, 450 and 510 ESCC cell lines. Meanwhile, the GSK-3 $\beta$ expression was downregulated. ${ }^{11}$ Xue et al proved that blocking $W n t / \beta$-catenin pathway could significantly inhibit cell proliferation and metastasis and promote cell apoptosis in ESCC. ${ }^{12}$ Therefore, the critical molecules that belong to these two signaling pathways may be of great significance in ESCC treatment.

$\beta$-arrestins, members of the arrestin family of proteins, consist of $\beta$-arrestin 1 and $\beta$-arrestin 2 . $\beta$-arrestins are widely expressed intracellular adaptor and scaffolding proteins involved in the regulation of G Protein-Coupled Receptor (GPCR) desensitization, internalization, intracellular trafficking, and $G$ protein-independent signaling. ${ }^{13}$ Meanwhile, $\beta$-arrestins can act as signaling molecules which play a critical role in regulating metabolic functions. ${ }^{14}$ Recent researches showed that $\beta$-arrestins widely involved in the tumor progression. ${ }^{15} \mathrm{~A}$ research indicated that $\beta$-arrestin1 could promote cell and tumor growth in prostate cancer. ${ }^{16}$ Niu et al demonstrated that $\beta$-arrestin1 could regulate cholesterol metabolism via the Akt-dependent pathway. ${ }^{17}$ Moreover, $\beta$-arrestin 1 could modulate EMT and GSK-3 $\beta / \beta$ catenin signaling pathway in prostate cancer. ${ }^{18}$

Based on the researches above, the present study aims to investigate the effect of $\beta$-arrestin1 on cell proliferation, invasion, migration and tumor growth in ESCC, and to provide a theoretical basis for the early prevention and treatment of ESCC.

\section{Materials and Methods Cell Culture}

HEEC, TE-1, ECA-109, KYSE-410 and KYSE-520 cell lines were purchased from the Institute of Biochemistry and Cell Biology (Shanghai, China). All cells lines were cultured in RPMI 1640 medium (Gibco, USA) containing $10 \% \mathrm{FBS}$ and $1 \%$ Penicillin/Streptomycin solution at $37^{\circ} \mathrm{C}$ in a humidified incubator with $5 \% \mathrm{CO}_{2}$.

\section{Xenograft Tumor Experiment}

BALB/c nude mice (4-6 weeks old) were purchased from the Shanghai Laboratory Animal Center (Shanghai, CN). ECA-109 cells transfected with $\beta$-arrestin1, NC or sh- $\beta$ arrestin1, sh-NC or $\beta$-arrestin1+LY294002 were collected after $24 \mathrm{~h}$ of incubation. Then $5 \times 10^{6}$ cells were subcutaneously injected into the hip back of mice. Every 5 days, the tumor xenografts were excised from 5 mice. Then, tumor volume and weight were measured. The tumor volumes were analyzed using the following formula: tumor volume $\left(\mathrm{mm}^{3}\right)=$ width $\left(\mathrm{mm}^{2}\right) \times$ length $(\mathrm{mm}) / 2$. The research project is approved by the Ethics Committee of People' Hospital of Central District of Jinan. All animal experiments were conducted according to the ethical guidelines of People' Hospital of Central District of Jinan and the “3R" principle.

\section{RNA Isolation and qRT-PCR}

Total RNA extraction from tumor tissues and cells was conducted with the Trizol reagent kit (Invitrogen, USA) according to the manufacturer's protocol. The corresponding cDNA performed using the reverse transcription Kit (Thermo Fisher Scientific, USA). qPCR assay was performed using SYBR Premix Ex Taq ${ }^{\mathrm{TM}}$ (TaKaRa, Japan) according to the instructions. PCR conditions were as follows: pre-denaturing at $95^{\circ} \mathrm{C}$ for $3 \mathrm{~min}, 40$ cycles of denaturing at $95^{\circ} \mathrm{C}$ for $20 \mathrm{sec}$, annealing at $60^{\circ} \mathrm{C}$ for $40 \mathrm{sec}$, and polymerization at $72^{\circ} \mathrm{C}$ for $30 \mathrm{sec}$. U6 and GAPDH were used as internal controls. The relative gene expression levels were calculated using the $2^{-\Delta \Delta \mathrm{Ct}}$ method. All experiments were performed in triplicate.

\section{Cell Viability Assay (Cell Count Kit-8 Assay)} Cell proliferation was measured by Cell Counting Kit-8 assay (CCK-8 assay, Beyotime, Shanghai, CN). Following the indicated transfection, cells at a density of $4 \times 10^{3}$ cells/ per well were seeded into 96-well plates with three replicates and incubated in a humidified incubator for 24,48 or 72h. Subsequently, $10 \mu \mathrm{L}$ CCK-8 solution and $90 \mu \mathrm{L}$ of complete medium were added to each well and cultured at $37^{\circ} \mathrm{C}$ for $1 \mathrm{~h}$. The absorbance at a wavelength of $450 \mathrm{~nm}$ was detected using a microplate reader (BioTek Instruments, Inc., Winooski, VT, USA).

\section{Immunohistochemistry Assay}

The tumor tissue samples were prepared using $4 \%$ paraformaldehyde, then embedded in paraffin after dehydration. The tissues were sectioned into $4 \mu \mathrm{m}$ slides, followed by dewaxing, hydration and heating in citrate buffer. Then, the endogenous peroxidase activity was blocked with $3 \%$ hydrogen peroxide for $10 \mathrm{~min}$. The slides were incubated with anti- $\beta$-arrestin 1 at $4{ }^{\circ} \mathrm{C}$ overnight after incubating with $5 \%$ goat serum for $0.5 \mathrm{~h}$. After immersing 3 times 
with PBST, the sections were incubated with secondary antibodies for $20 \mathrm{~min}$ at $37^{\circ} \mathrm{C}$. Finally, a DAB substrate kit was used to visualize the $\beta$-arrestin1. Images were captured under a microscope.

\section{Would Healing}

Cells $(4 \times 105$ cells/well) were cultured in 6 -well plates for $24 \mathrm{~h}$. When confluence reached $\sim 100 \%$, a vertical line was scraped in the cell monolayer using a $10-\mu \mathrm{L}$ pipette tip. The dead cells were washed twice with PBS and serum-free medium was added. At the designated times $(0 \mathrm{~h}$ and $72 \mathrm{~h}$ ), the area of migration was measured using a light microscope.

\section{Trans-Well Invasion Assay}

According to the manufacturer's protocol, cell invasion assays were performed using Matrigel invasion chamber. A $100-\mu \mathrm{L}$ cell suspension $\left(5 \times 10^{5} / \mathrm{mL}\right.$ in FBS-free medium) was seeded in the upper chambers and $1 \mathrm{~mL}$ medium containing 10\% FBS was added to the lower chambers. After $24 \mathrm{~h}$, the cells remaining in the upper chamber were removed and inserts were fixed in methanol for $10 \mathrm{~min}$. Then, the cells were stained with $0.1 \%$ crystal violet for 30 min. The number of invasive cells was counted under a light microscope.

\section{Western Blot Assay}

Total proteins were isolated from the cultured cells or tumor xenografts using Radio-Immunoprecipitation Assay (RIPA). Then, the protein concentrations were determined using a BCA protein assay kit (Beyotime, $\mathrm{CN}$ ). Equal amount of protein was separated using 10\% SDS-PAGE, transferred onto PVDF membranes and blocked in 5\% non-fat milk for $1 \mathrm{~h}$. Then the membranes were incubated over night at $4{ }^{\circ} \mathrm{C}$ with the following primary antibodies: $\beta$-arrestin $1, \mathrm{p}-\mathrm{AKT}$, AKT, p-GSK3 $\beta$, GSK3 $\beta$, $\beta$-catenin, cyclinD1, CDK2, P21, MMP2, MMP9, E-cad, N-cad, vimentin, SANI1 and GAPDH. Next, the membranes were incubated with peroxidase-conjugated secondary antibodies for $1.5 \mathrm{~h}$ at room temperature. The proteins were visualized with an enhanced chemiluminescence reagent.

\section{Statistical Analysis}

Statistical analysis was performed using GraphPad Prism 6.01 software (GraphPad Software Inc.). Differences among three or more groups were analyzed by one- way analysis of variance (one-way ANOVA) followed by Tukey's post hoc test and all quantitative data were presented as mean \pm standard deviation. A p-value of less than 0.05 was considered to indicate a statistically significant difference.

\section{Results}

$\beta$-Arrestin I Is Aberrantly Upregulated in Human ESCC Tissues and Cell Lines and Regulates the AKT/GSK $3 \beta / \beta$-Catenin Signaling Pathway

To confirm that $\beta$-arrestin1 was differentially expressed in ESCC, Western blot was applied to determine the expression level of $\beta$-arrestin1 in ESCC tissues and cell lines. As shown in Figure 1A, $\beta$-arrestin1 was highly expressed in ESCC tissues compared with adjacent normal tissues. Besides, $\beta$-arrestin1 expression levels were detected in the four ESCC cell lines TE-1, ECA-109, KYSE-410 and KYSE-520, and a normal esophageal epithelial cell line HEEC. As demonstrated in Figure 1B, $\beta$-arrestin 1 expression levels were higher in ESCC cell lines compared with those in HEEC cells, and $\beta$-arrestin1 expression level in ECA-109 was the most obvious among them.

In order to investigate how $\beta$-arrestin1 regulates the signaling associated with cellular processes, transfection of sh- $\beta$ arrestin1 or pcDNA- $\beta$-arrestin1 into ECA-109 cells was used to investigate the functional role of $\beta$-arrestin1. As shown in Figure $1 \mathrm{C}$ and $\mathrm{D}, \beta$-arrestin 1 expression was significantly downregulated in ECA-109 cells transfected with sh- $\beta$ arrestin1 compared with the shRNA group. By contrast, $\beta$ arrestinl expression was markedly upregulated by transfecting with pcDNA- $\beta$-arrestin1. As presented in Figure $1 \mathrm{E}$ and $\mathrm{F}$, the effects of $\beta$-arrestin1 on $\mathrm{AKT} / \mathrm{GSK} 3 \beta / \beta$-catenin signaling pathway were determined by Western Blot and qPCR. The results revealed that inhibition of $\beta$-arrestin1 decreased the levels of $\mathrm{p}$-AKT, $\mathrm{p}$ - GSK3 $\beta$ and $\beta$-catenin. Also, $\beta$-arrestin1 overexpression significantly promoted AKT/GSK3 $\beta / \beta$ catenin pathway activation, while LY294002 (a PI3K inhibitor) could reverse the effect of pcDNA- $\beta$-arrestin 1 .

\section{$\beta$-Arrestin I Regulates Proliferation, Migration, Invasion and EMT of ESCC Cells} To evaluate the role of $\beta$-arrestin1 in ESCC cell proliferation, the cell viability was evaluated by CCK- 8 assay (Figure 2A). Cell growth curve assay revealed that cells transfected with pcDNA- $\beta$-arrestin1 grew more rapidly than the control group, while sh- $\beta$-arrestin 1 inhibited the cell growth compared to the control. Furthermore, LY294002 inhibited the effect of $\beta$-arrestin1. In order to 
A

$\beta$-arrestin1

GAPDH

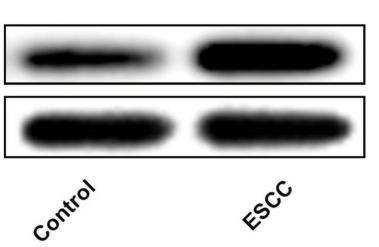

$\beta$-arrestin1

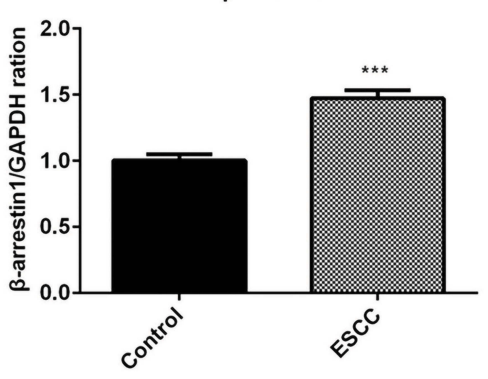

D

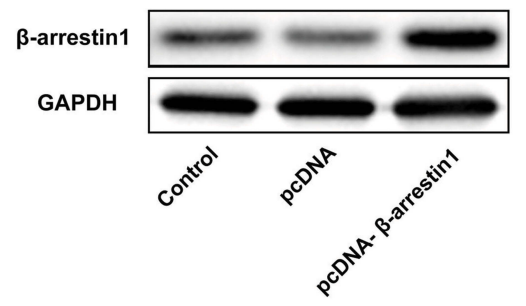

F

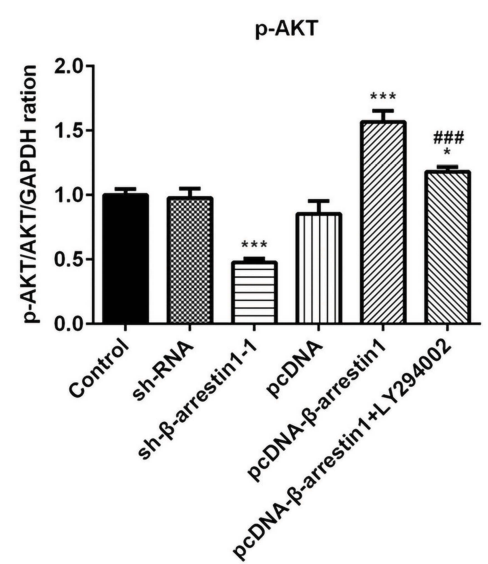

B

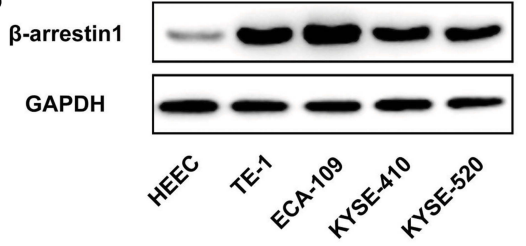

$\beta$-arrestin1
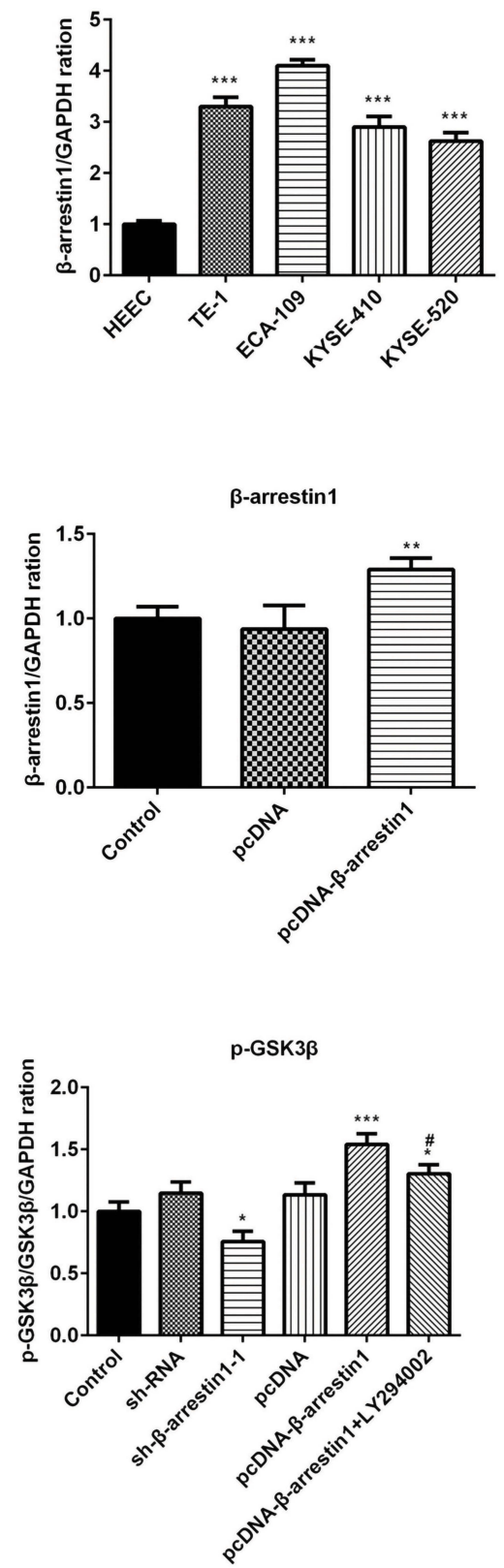

C

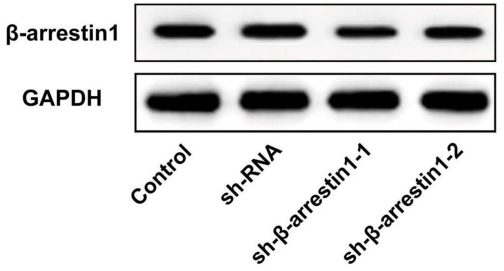

$\beta$-arrestin1

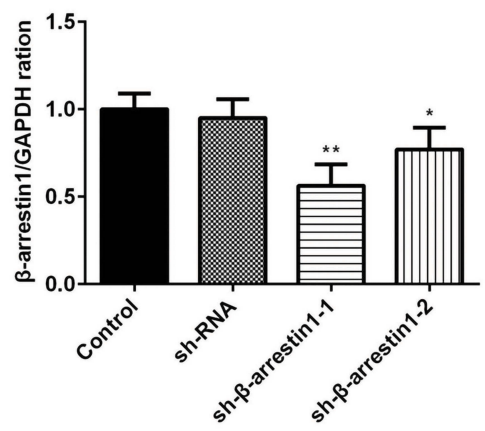

E
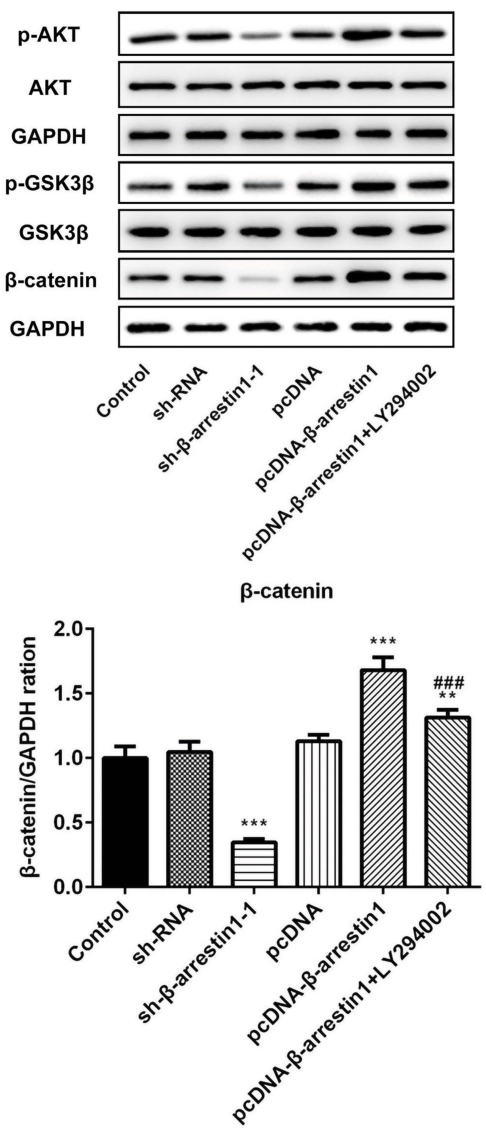

Figure I $\beta$-arrestin I is aberrantly upregulated in human ESCC tissues and cell lines and regulates the AKT/GSK3// $\beta$-catenin signaling pathway. (A) Western Blot analysis of $\beta$-arrestin I expression in tumor tissues and adjacent normal tissues in patients with ESCC. (B) Western Blot analysis of $\beta$-arrestin I expression in the four ESCC cell lines TE-I, ECA-109, KYSE-4I0 and KYSE-520, and a normal esophageal epithelial cell line HEEC. (C) ECA-109 cells were transfected with sh-NC, sh- $\beta$-arrestinI-I and sh- $\beta$ arrestin I-2, and the expression of $\beta$-arrestin I was determined using Western blot. (D) ECA-109 cells were transfected with pcDNA-NC and pcDNA- $\beta$-arrestin I, and the expression of $\beta$-arrestin I was determined using Western blot. (E) The protein expressions of p-AKT, AKT, p-GSK3 $\beta$, GSK3 $\beta$ and $\beta$-catenin were measured by Western

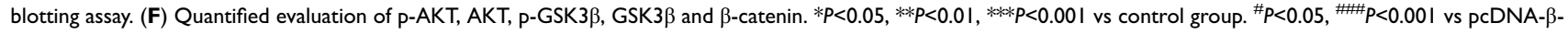
arrestin I group. 


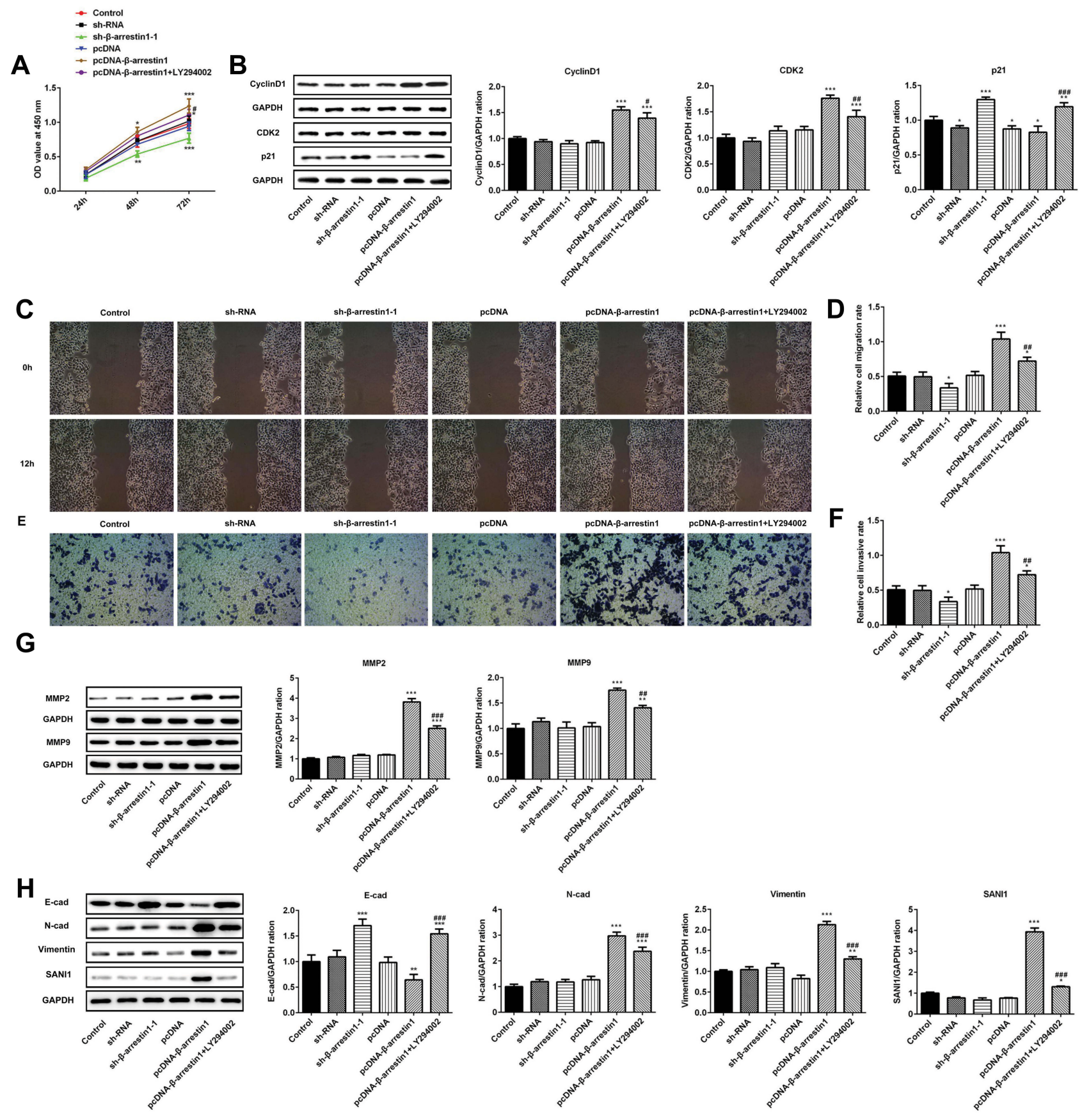

Figure $2 \beta$-arrestin I regulates proliferation, migration, invasion and EMT of ESCC cells. (A) The cell proliferation ability was determined by Cell Counting kit-8 (CCK-8) assay. (B) The protein expressions of cyclinDI, CDK2 and p2I were measured by Western blotting assay. (C) Wound healing assays were performed to determine cell migration. (D) Quantitative results regarding the cell migration. (E) Trans-well assays were performed to determine cell invasion. (F) Quantitative results regarding the cell invasion. (G) The protein levels of MMP2 and MMP9 were measured by Western blotting assay. (H) The protein levels of E-cad, N-cad, vimentin and SANII were measured by Western blotting assay. ${ }^{*} P<0.05, * * P<0.01, * * * P<0.001$ vs control group. ${ }^{\#} P<0.05,{ }^{\#} P<0.01,{ }^{\# \#} P<0.001$ vs $P C D N A-\beta$-arrestin I group.

explain the effect of $\beta$-arrestin1 on cell proliferation, we further examined the expression of several cell-cycle regulatory proteins. The results showed that the expression level of CyclinD1 and CDK2 were positively related to the expression level of $\beta$-arrestin1 (Figure 2B), while p21 was negatively related to $\beta$-arrestin1 expression.
To assess the role of $\beta$-arrestin1 on the migration and invasion of ESCC cells, three different approaches were performed. Firstly, wound healing assay was used to evaluate the migration of ESCC cells (Figure 2C and D). Relative ratios of wound closures were markedly promoted after transfected with $\beta$-arrestin1 plasmid. While sh- $\beta$-arrestin1 and LY294002 
inhibited the cell migration. Secondly, transwell assay was applied to investigate the role of $\beta$-arrestin1 on cell invasion. In the invasion assay, sh- $\beta$-arrestin1 transfected cells showed a decreased invasive ability while overexpression of $\beta$-arrestin1 significantly promoted the invasion of ESCC cells (Figure $2 \mathrm{E}$ and $\mathrm{F}$ ). We also found that $\beta$-arrestin 1 significantly increased the expressions of MMP2 and MMP9 in Western Blot (Figure 2G). Besides, knockdown of $\beta$-arrestin1 inhibited the protein levels of MMP2 and MMP9. All the effects of $\beta$-arrestin 1 on cell migration and invasion were reversed by LY294002.

To assess the effect of $\beta$-arrestin1 on EMT, the protein expression of E-cad, N-cad, vimentin and SANI1 was checked in ESCC cells using Western Blot. Our study found that overexpression of $\beta$-arrestin1 significantly increased the protein expression of $\mathrm{N}$-cad, vimentin and SANI1, and reduced the expression of E-cad (Figure 2H). However, knockdown of $\beta$-arrestin1 showed an opposite effect and LY294002 could inhibit the effect of $\beta$-arrestin1 on cell EMT.

\section{$\beta$-Arrestin I Regulates Tumor Growth in vivo Model of ESCC}

The vivo model of ESCC was applied to further examine the potential role of $\beta$-arrestin1. As shown in Figure 3A and B, compared with the control group, $\beta$-arrestin 1 expression was significantly downregulated in vivo model of ESCC after transfection with sh- $\beta$-arrestin1-1. By contrast, $\beta$-arrestin1 expression was markedly upregulated in vivo model of ESCC after transfection with pcDNA- $\beta$-arrestin1. To examine the expression of $\beta$-arrestin 1 in ESCC xenografts, tissues were analyzed using IHC. The IHC results in Figure $3 \mathrm{C}$ showed a significant loss of $\beta$-arrestin1 expression in sh- $\beta$ arrestin1 group compared with the control group, which was reversed by pcDNA- $\beta$-arrestin 1 treatment. Whereas, LY294002 could reduce the expression of $\beta$-arrestin1. As shown in Figure 3D-F, monitoring of tumor growth for approximately $20 \mathrm{~d}$ post-injection revealed a significant reduction in growth in sh- $\beta$-arrestin1 group compared with the control group, which was reversed in pcDNA- $\beta$-arrestin1 group. In addition, LY294002 inhibited the effect of $\beta$ arrestin1 on promoting tumor growth.

\section{$\beta$-Arrestin I Regulates Tumor Migration and Invasion in vivo Model of ESCC}

To evaluate the effects of $\beta$-arrestin1 on tumor migration and invasion in vivo model of ESCC, the related proteins were examined by Western Blot. The data suggested that $\beta$-arrestin1 increased the protein levels of MMP2, MMP9, N-cad, vimentin and SANI1, and reduced the expression of E-cad (Figure 4A and B). $\beta$-arrestin1 interference and LY294002 inhibited the tumor migration and invasion in vivo. All the results described above were consistent with the results in vitro.

\section{Discussion}

ESCC is one of the most fatal malignant tumors in digestive system. Although researches in the early diagnosis of ESCC, as well as surgical treatment, local and systemic adjuvant therapy and other aspects have made a great advance, the morbidity and mortality of esophageal squamous cell carcinomas remain high. And the tumor invasion and metastasis are still the main causes for the patients' deaths. $^{1,3,5}$ In recent years, researches showed a sharp relationship between $\beta$-arrestin1 and pathological courses of various tumors. ${ }^{19,20}$ This study revealed that the protein level of $\beta$-arrestin1 was drastically higher in ESCC tissues than in adjacent tissues. Besides, the expression difference in tissues was consistent with it between ESCC cells and normal esophageal epithelial cells.

The fact that PI3K/Akt and $\mathrm{Wnt} / \beta$-catenin pathways are closely associated with cancers has been commonly known. $\mathrm{PI} 3 \mathrm{~K} / \mathrm{Akt}$ and $\mathrm{Wnt} / \beta$-catenin signaling pathway inhibitors, as newly emerged targeted drugs in recent years, provide a new treatment scheme for various common tumors. ${ }^{21,22}$ Moreover, researches indicated that $\beta$-arrestin1 could affect Aktdependent pathway and GSK-3 $\beta / \beta$-catenin signaling. ${ }^{17,18} \mathrm{We}$ evaluated that overexpression of $\beta$-arrestin 1 markedly promoted the activation of $\mathrm{AKT} / \mathrm{GSK} 3 \beta / \beta$-catenin pathway, while knockdown of $\beta$-arrestin1 reversed this effect.

Recently, it has been demonstrated that $\beta$-arrestin1 could promote the proliferation of prostate cancer cells, while downregulation of $\beta$-arrestin 1 suppressed glioblastoma cell malignant progression. ${ }^{16,23}$ Similarly, our results revealed that pcDNA- $\beta$-arrestin1 improved ESCC cell proliferation and tissue growth of transplanted tumors. EMT has been regarded as a crucial factor for the development of metastasis of human tumors. ${ }^{24}$ Wang et al studied that $\beta$-arrestin 1 was strikingly correlated with lymph nodal metastasis and pathological lymph nodal staging. ${ }^{25}$ As expected, the results revealed that $\beta$-arrestin 1 could promote the migration and invasion of ESCC cells. What's more, $\beta$-arrestin 1 accelerated the process of EMT in ESCC cells and subcutaneous xenotransplanted tumors, while $\beta$-arrestin1 interference could inhibit migration, invasion and process of EMT in ESCC. 


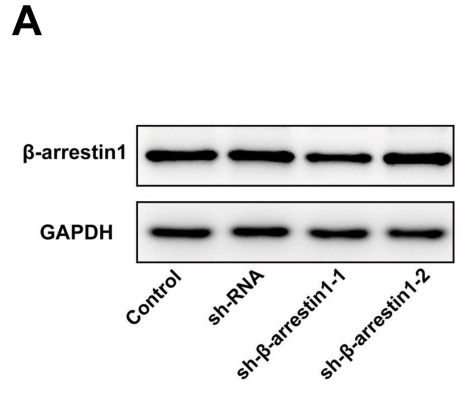

C

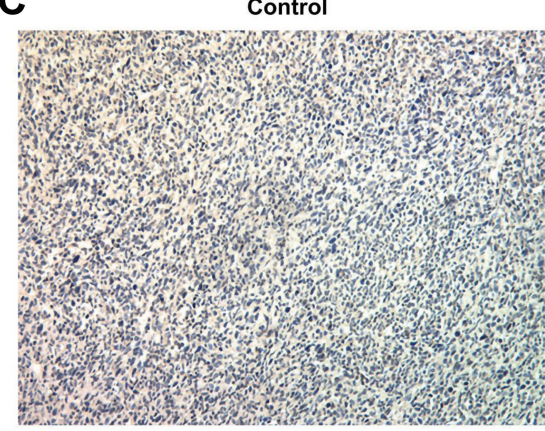

pcDNA

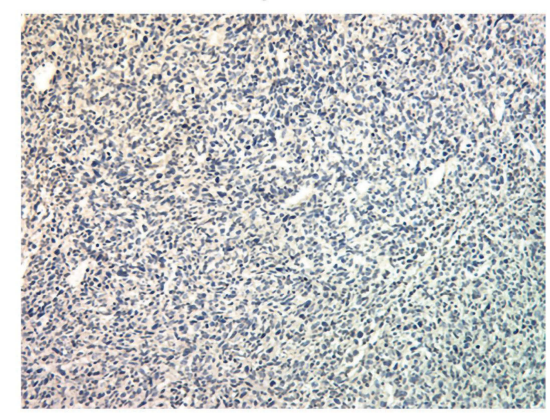

D

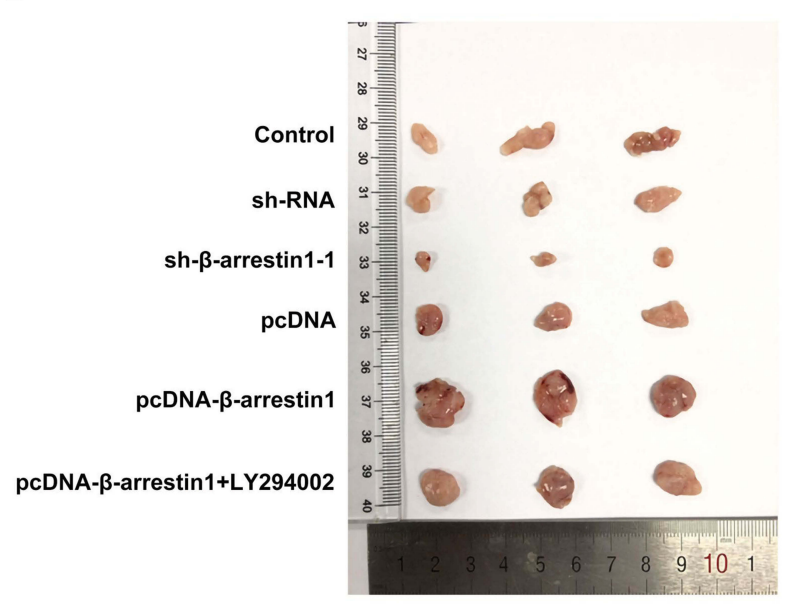

B

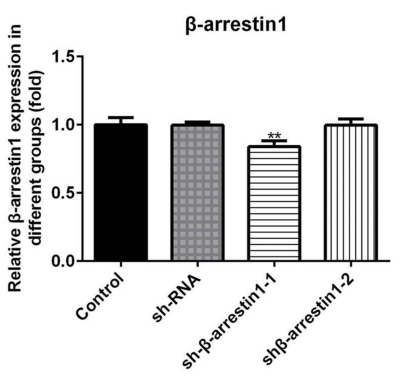

sh-RNA

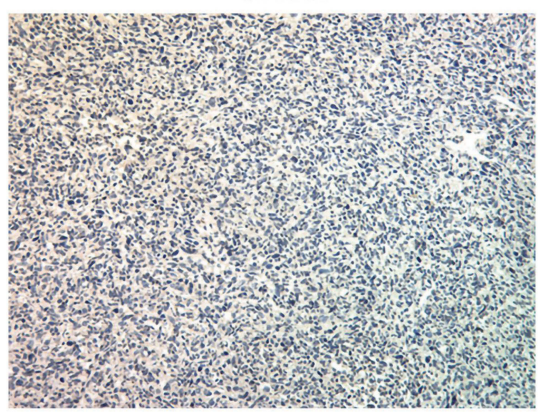

pcDNA- $\beta$-arrestin 1

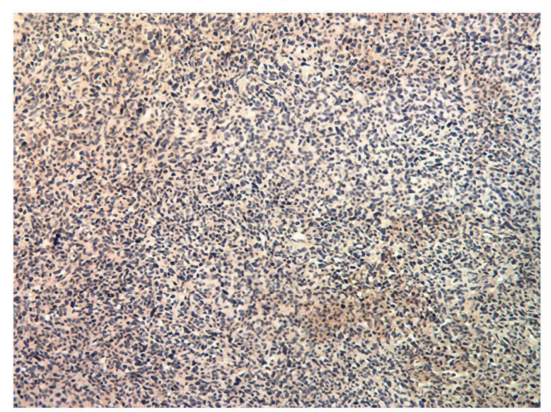

$\beta$-arrestin1

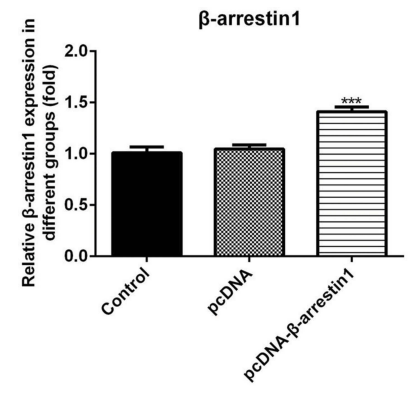

sh- $\beta$-arrestin1-1

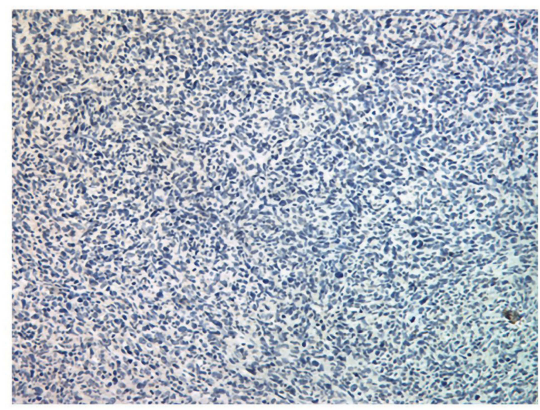

pcDNA- $\beta$-arrestin 1+LY294002

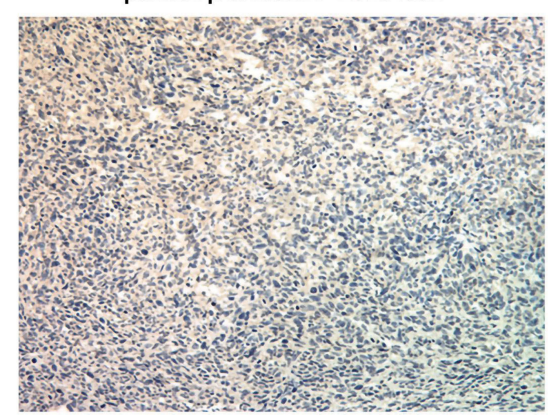

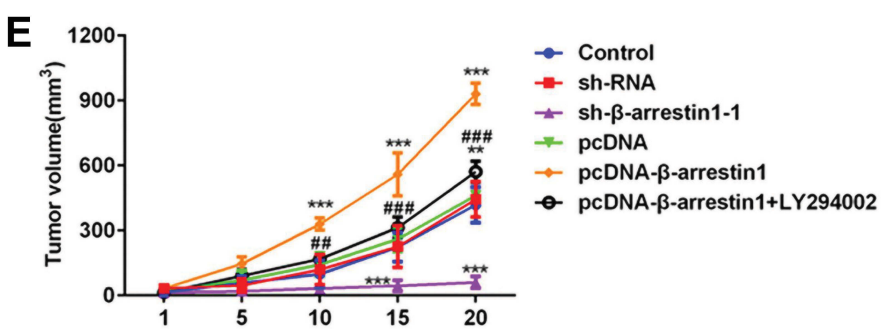

$\mathbf{F}$

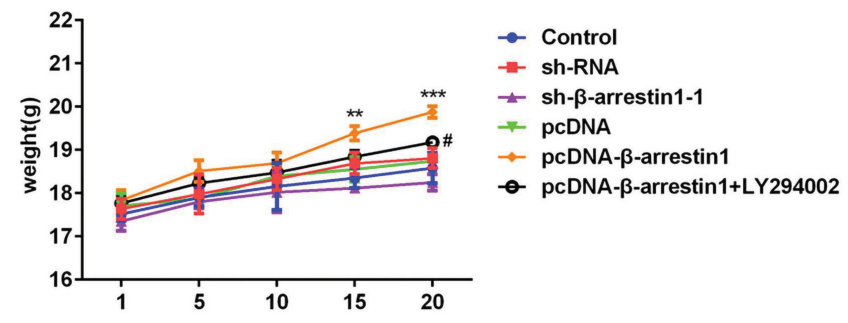

Figure $3 \beta$-arrestin I regulates tumor growth in vivo model of ESCC. (A) $\beta$-arrestin I expression level in vivo model of ESCC after transfection with sh-NC, sh- $\beta$-arrestin I-I and sh- $\beta$-arrestin I-2 was determined using Western blot. (B) $\beta$-arrestin I expression level in vivo model of ESCC after transfection with pcDNA-NC and pcDNA- $\beta$-arrestin I was determined using Western blot. (C) $\beta$-arrestin I level was determined using immunohistochemistry assay. (D) Photographs of tumor tissues from different groups. (E) Growth curves of tumor volumes in xenografts of nude mice were determined based on tumor volume measured every 5 days. (F) Growth curves of tumor weights in xenografts of nude mice were determined based on tumor weight detected every 5 days. ${ }^{* * P} P<0.01,{ }^{* * * P} P<0.001$ vs control group. ${ }^{\#} P<0.05,{ }^{\# \#} P<0.01$, ${ }^{\# \#} P<0.001$ vs $P C D N A-$ $\beta$-arrestin I group. 
A
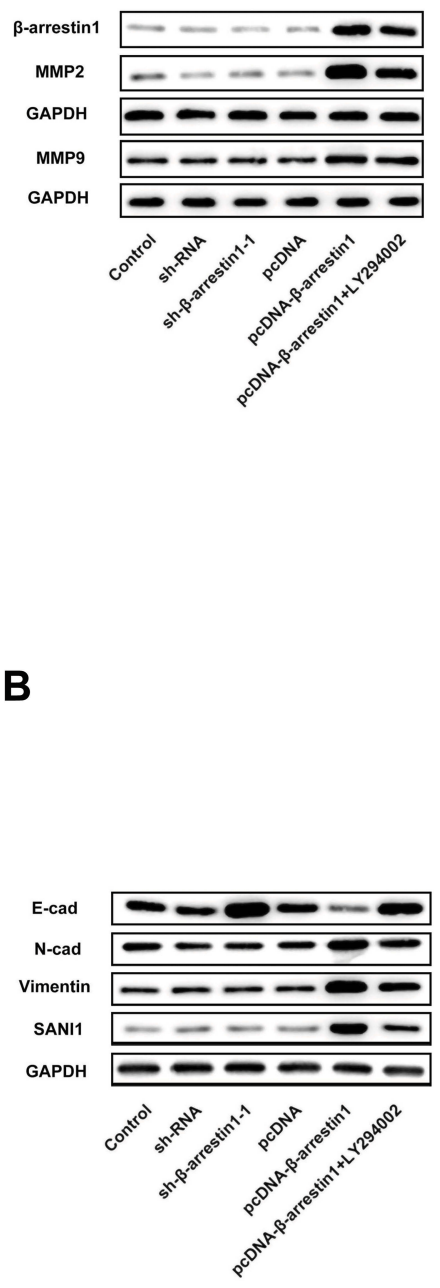

B
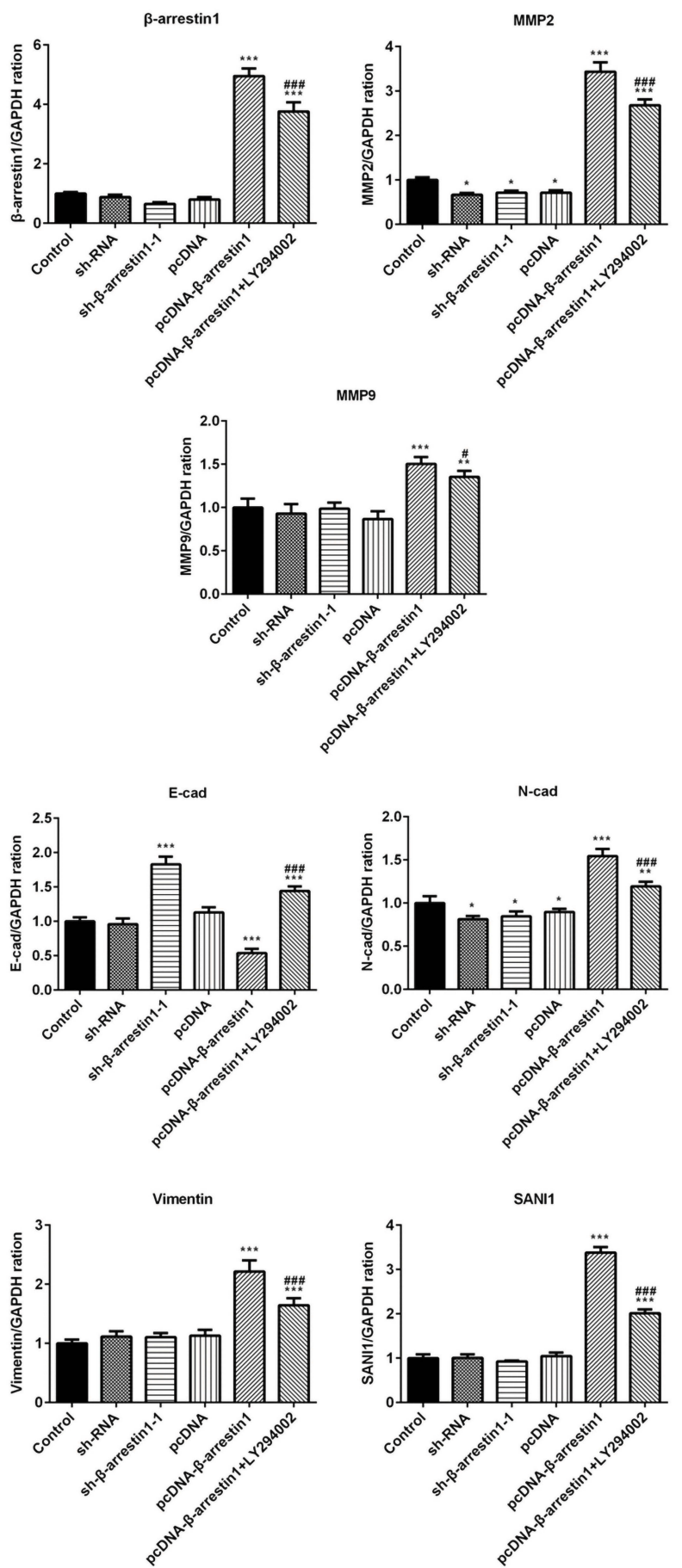

Figure $4 \beta$-arrestin I regulates tumor migration and invasion in vivo model of ESCC. (A) The protein levels of $\beta$-arrestin I, MMP2 and MMP9 were measured by Western blotting assay. (B) The protein expressions of E-cad, N-cad, vimentin and SANII were measured by Western blotting assay. $* P<0.05$, $* * P<0.01$, $* * * P<0.00$ I vs control group. ${ }^{\#} P<0.05,{ }^{\# \#} P<0.001$ vs $p c D N A-\beta$-arrestin I group.

Our current study is an investigation of the potential significance and biological mechanisms of $\beta$-arrestin 1 in ESCC. We will further use our cell and tissue samples to verify other effects of $\beta$-arrestin 1. Our data revealed that $\beta$-arrestin 1 could affect the development of ESCC by regulating AKT/GSK3 $\beta / \beta$-catenin pathway, which may provide a novel strategy in ESCC treatment. 


\section{Data Sharing Statement}

The analyzed data sets generated during the present study are available from the corresponding author on reasonable request.

\section{Funding}

Shandong Key Research and Development Program (2016GSF201004).

\section{Disclosure}

The authors declare that they have no competing interests.

\section{References}

1. Di Pardo BJ, Bronson NW, Diggs BS, Thomas CR Jr, Hunter JG, Dolan JP. The global burden of esophageal cancer: a disability-adjusted life-year approach. World J Surg. 2016;40(2):395-401. doi:10.1007/ s00268-015-3356-2

2. Zhao P, Yan W, Fu H, Lin Y, Chen KN. Efficacy of postoperative adjuvant chemotherapy for esophageal squamous cell carcinoma: a meta-analysis. Thorac Cancer. 2018;9(8):1048-1055. doi:10.1111/ 1759-7714.12787

3. Kashima H, Noma K, Ohara T, et al. Cancer-associated fibroblasts (CAFs) promote the lymph node metastasis of esophageal squamous cell carcinoma. Int J Cancer. 2019;144(4):828-840. doi:10.1002/ijc.31953

4. Abnet CC, Arnold M, Wei WQ. Epidemiology of esophageal squamous cell carcinoma. Gastroenterology. 2018;154(2):360-373. doi:10.1053/j.gastro.2017.08.023

5. Pang L, Li Q, Wei C, et al. TGF- $\beta 1 /$ Smad signaling pathway regulates epithelial-to-mesenchymal transition in esophageal squamous cell carcinoma: in vitro and clinical analyses of cell lines and nomadic Kazakh patients from northwest Xinjiang, China. PLoS One. 2014;9(12):e112300. doi:10.1371/journal.pone.0112300

6. Yang L, Wang T, Zhang J, Wang X. BTBD7 silencing inhibited epithelial- mesenchymal transition (EMT) via regulating Slug expression in human salivary adenoid cystic carcinoma. Cancer Biomark. 2017;20(4):461-468. doi:10.3233/CBM-170262

7. Warns JA, Davie JR, Dhasarathy A. Connecting the dots: chromatin and alternative splicing in EMT. Biochem Cell Biol. 2016;94 (1):12-25. doi:10.1139/bcb-2015-0053

8. $\mathrm{Wu} \mathrm{Z}, \mathrm{Lu} \mathrm{H}$, Yao J, et al. GABARAP promotes bone marrow mesenchymal stem cells-based the osteoarthritis cartilage regeneration through the inhibition of PI3K/AKT/mTOR signaling pathway J Cell Physiol. 2019;234(11):21014-21026. doi:10.1002/jcp.v234.11

9. Zhao Q, Gao S, Du Q, Liu Y, Du Q, Liu Y. Long non-coding RNA SNHG20 promotes bladder cancer via activating the $\mathrm{Wnt} / \beta$-catenin signalling pathway. Int $J$ Mol Med. 2018;42(5):2839-2848. doi:10.3892/ijmm.2018.3819

10. Pan J, Fan Z, Wang Z, et al. CD36 mediates palmitate acid-induced metastasis of gastric cancer via AKT/GSK-3 $\beta / \beta$-catenin pathway. $J$ Exp Clin Cancer Res. 2019;38(1):52. doi:10.1186/s13046-019-1049-7
11. Liu X, Song M, Wang P, et al. Targeted therapy of the AKT kinase inhibits esophageal squamous cell carcinoma growth in vitro and in vivo. Int J Cancer. 2019;145(4):1007-1019. doi:10.1002/ijc.32285

12. Xue JJ, Zhang LY, Hou HJ, Li Y, Liang WS, Yang KH. Protective effect of propofol on hydrogen peroxide-induced human esophageal carcinoma via blocking the $\mathrm{Wnt} / \beta$-catenin signaling pathway. Iran J Basic Med Sci. 2018;21(12):1297-1304. doi:10.22038/ijbms. 2018.29141.7039

13. Perkovska S, Méjean C, Ayoub MA, et al. V1b vasopressin receptor trafficking and signaling: role of arrestins, $\mathrm{G}$ proteins and Src kinase. Traffic. 2018;19(1):58-82. doi:10.1111/tra.12535

14. Pydi SP, Jain S, Tung W, et al. Adipocyte $\beta$-arrestin-2 is essential for maintaining whole body glucose and energy homeostasis. Nat Commun. 2019;10(1):2936. doi:10.1038/s41467-019-11003-4

15. Hu S, Wang D, Wu J, Jin J, Wei W, Sun W. Involvement of $\beta$-arrestins in cancer progression. Mol Biol Rep. 2013;40(2):1065-1071. doi:10.1007/ s11033-012-2148-0

16. Kong Z, Deng T, Zhang M, et al. $\beta$-arrestin1-medieated inhibition of FOXO3a contributes to prostate cancer cell growth in vitro and in vivo. Cancer Sci. 2018;109(6):1834-1842. doi:10.1111/cas.2018.109.issue-6

17. Niu S, Li H, Chen W, Zhao J, Gao L, Bo T. Beta-arrestin 1 mediates liver thyrotropin regulation of cholesterol conversion metabolism via the Akt-dependent pathway. Int J Endocrinol. 2018;2018:4371396. doi:10.1155/2018/1528437

18. Duan X, Zhang T, Kong Z, et al. $\beta$-arrestin1 promotes epithelialmesenchymal transition via modulating GSK-3 $\beta / \beta$-catenin pathway in prostate cancer cells. Biochem Biophys Res Commun. 2016;479 (2):204-210. doi:10.1016/j.bbrc.2016.09.039

19. Wang L, Wang K, Dong W, Shen H, Du J. Regulation of response to radiotherapy by $\beta$-arrestin 1 in non-small cell lung cancer. $J$ Cancer. 2019;10(17):4085-4095. doi:10.7150/jca.30012

20. Liu Z, Jiang J, He Q, et al. $\beta$-Arrestin1-mediated decrease in endoplasmic reticulum stress impairs intestinal stem cell proliferation following radiation. FASEB J. 2019;33(9):10165-10176. doi:10.10 96/fj.201900376RRR

21. Hainsworth JD, Becker KP, Mekhail T, et al. Phase I/II study of bevacizumab with BKM120, an oral PI3K inhibitor, in patients with refractory solid tumors (phase I) and relapsed/refractory glioblastoma (phase II). J Neurooncol. 2019;144(2):303-311. doi:10.1007/s11060019-03227-7

22. Pak S, Park S, Kim Y, et al. The small molecule WNT/ $\beta$-catenin inhibitor CWP232291 blocks the growth of castration-resistant prostate cancer by activating the endoplasmic reticulum stress pathway. $J$ Exp Clin Cancer Res. 2019;38(1):342. doi:10.1186/s13046-019-1342-5

23. Lan T, Wang H, Zhang Z, et al. Downregulation of $\beta$-arrestin 1 suppresses glioblastoma cell malignant progression vis inhibition of Src signaling. Exp Cell Res. 2017;357(1):51-58. doi:10.1016/j.yexcr. 2017.04.023

24. López-Novoa JM, Nieto MA. Inflammation and EMT: an alliance towards organ fibrosis and cancer progression. EMBO Mol Med. 2009;1(6-7):303-314. doi:10.1002/emmm.200900043

25. Wang LG, Su BH, Du JJ. Expression of $\beta$-arrestin 1 in gastric cardiac adenocarcinoma and its relation with progression. Asian Pac J Cancer Prev. 2012;13(11):5671-5675. doi:10.7314/APJCP.2012.13.11.5671

OncoTargets and Therapy

Dovepress

\section{Publish your work in this journal}

OncoTargets and Therapy is an international, peer-reviewed, open access journal focusing on the pathological basis of all cancers, potential targets for therapy and treatment protocols employed to improve the management of cancer patients. The journal also focuses on the impact of management programs and new therapeutic

agents and protocols on patient perspectives such as quality of life, adherence and satisfaction. The manuscript management system is completely online and includes a very quick and fair peer-review system, which is all easy to use. Visit http://www.dovepress.com/ testimonials.php to read real quotes from published authors. 